\title{
Obesity and Its Relationship with Occupational Injury in the Canadian Workforce
}

\author{
Ian Janssen, ${ }^{1,2}$ Eric Bacon, ${ }^{1}$ and William Pickett ${ }^{2,3}$ \\ ${ }^{1}$ School of Kinesiology and Health Studies, Queen's University, Kingston, ON, Canada K7L 3N6 \\ ${ }^{2}$ Department of Community Health and Epidemiology, Queen's University, Kingston, ON, Canada K7L 3N6 \\ ${ }^{3}$ Department of Emergency Medicine, Queen's University, Kingston, ON, Canada K7L 3N6 \\ Correspondence should be addressed to Ian Janssen, ian.janssen@queensu.ca \\ Received 25 March 2011; Accepted 20 May 2011 \\ Academic Editor: Linda McCargar
}

Copyright (C) 2011 Ian Janssen et al. This is an open access article distributed under the Creative Commons Attribution License, which permits unrestricted use, distribution, and reproduction in any medium, provided the original work is properly cited.

Objectives. To examine associations between obesity and occupational injury. Methods. Participants consisted of a representative sample of 7,678 adult Canadian workers. Participants were placed into normal weight, overweight, and obese categories based on their body mass index. Different injury types, location, and external causes were measured. Logistic regression was used to estimate relationships. Results. By comparison to normal weight workers, obese workers were more likely to report any occupational injuries (odds ratio (OR) 1.40, 95\% confidence interval (CI): 0.98-1.99) and serious occupational injuries (1.49, 0.99-2.26). These relationships were more pronounced for sprains and strains $(1.80,1.04-3.11)$, injuries to the lower limbs $(2.14,1.12-4.11)$ or torso $(2.36,1.13-4.93)$, and injuries due to falls $(2.10,0.86-5.10)$ or overexertion $(2.08,0.96-4.50)$. Female workers, workers $\geq 40$ years, and workers employed in sedentary occupations were particularly vulnerable. Increased risks were not identified for overweight workers. Conclusions. Obese workers experienced 40-49\% higher risks for occupational injury.

\section{Introduction}

Obesity is a leading public health problem and an obvious health research priority. In our own country of Canada, one in four adults are obese, six in ten are overweight or obese, and rates of childhood obesity have tripled over the past 25 years [1,2]. Health consequences of obesity require focused study to fully understand its societal impact. The influence of obesity on the occurrence of chronic diseases such as cardiovascular disease and type 2 diabetes are well established [3-5].There are also a number of acute health outcomes associated with obesity that remain unappreciated. One such outcome is unintentional injury.

Links between obesity and injury, particularly injuries occurring in occupational settings, are of direct societal interest. The economic burden of obesity in Canada is estimated at more than $\$ 4$ billion annually; much of this figure is attributable to lost productivity due to worker absenteeism [6]. A number of studies have examined the association between obesity and injuries occurring within the occupational setting [7-10]. These studies report that obese persons are $26-107 \%$ more likely to have had an occupational injury than their normal weight counterparts. However, existing studies are limited in terms of the cross-sectional designs employed, small sample sizes (i.e., $<3000$ participants), the narrow breadth of the workforce studied (i.e., material handlers, firefighters, and aluminum manufacturers), and the lack of consideration of different injury types and locations.

We therefore developed a national longitudinal study that aimed to quantify the associations between obesity and the occurrence of occupational injury in Canada. Through this research, we hoped for further understanding of the health impacts of obesity that in turn might inform the development and targeting of interventions aimed at the prevention of injury in occupational settings.

\section{Participants and Methods}

2.1. Theoretical Framework. Much of the existing literature that examines the link between obesity and injury lacks a theoretical base. To address this shortcoming, we previously developed a biophysical framework [11]. Based on existing evidence, this framework established that obesity is associated with (1) a number of risk factors for unintentional 
injury (increased comorbidities [12], increased use of psychotropic medications [13], altered gait and balance [14], increased forces involved in falls, lower neural sensitivity [15], greater extremity friction [16], and sleep apnea and fatigue [17]) as well as (2) some protective factors that will help prevent injury (greater bone density [18] and increased cushioning during falls from excess fat). We hypothesized that, for many occupational injury types, the risk factors will outweigh the protective factors, resulting in an increased injury risk in obese and perhaps overweight individuals.

2.2. Study Population. The National Population Health Survey (NPHS) is a nationally representative, longitudinal survey conducted every two years across Canada beginning in June, 1994 [19]. The NPHS covers household and institutional residents in all provinces and territories, except persons living on Indian reserves, on Canadian Forces bases, and in some remote areas. It consists of a detailed home or telephone interview and requests information on disability, diseases, injuries, mental health, and well-being. The cohort used in this analysis consisted of adults (aged $\geq 18$ years) in the workforce as determined by the question "Have you worked for pay or profit at any time in the past 12 months?". In addition, participants had to have a recorded body mass index (BMI) in the 1998 cycle and responded to the injury questions in the 2000 cycle. The 1998 cycle was chosen as the baseline due to the lack of comprehensive injury data collected prior to the 2000 cycle. This study therefore consisted of a longitudinal analysis that examined how BMI status in 1998 predicted reports of occupational injury in 2000 within the working population.

2.3. Overweight and Obesity. Body mass index (BMI = weight/height ${ }^{2}$ ), which is the most commonly used indicator of obesity, was calculated based on self-reported weight and height. As BMI determined from self-reported height and weight is significantly lower than BMI determined from measured values, self-reported BMI was corrected to reflect measured values using the following formulas for men $\left(\mathrm{BMI}_{\text {(measured })}=-1.08+1.08 \mathrm{BMI}_{\text {(self-reported })}\right)$ and women $\left(\mathrm{BMI}_{\text {(measured })}=-0.12+1.05 \mathrm{BMI}_{(\text {self-reported })}\right)$ [20]. Standard BMI thresholds were used to create normal weight $\left(18.5-24.9 \mathrm{~kg} / \mathrm{m}^{2}\right)$, overweight $\left(25-29.9 \mathrm{~kg} / \mathrm{m}^{2}\right)$, and obese $\left(\geq 30 \mathrm{~kg} / \mathrm{m}^{2}\right)$ BMI categories [21, 22]. Underweight individuals $\left(\leq 18.49 \mathrm{~kg} / \mathrm{m}^{2}\right)$, who represented $1.7 \%$ of the study sample, were excluded because the mechanisms linking a low weight to injury are different from the mechanisms that link excessive weight to injury.

2.4. Occupational Injury. Participants in the workforce were asked to list injuries that had occurred in the past 12 months that were serious enough to limit their normal activities. A series of follow-up questions were then asked, for the most serious injury, for those who reported having at least one injury. For the purposes of this study, respondents were considered to have occupational injuries if the answer to question "What type of activity were you doing when you were injured?" was "Working at a job or business (include travel to or from work)." The injury was determined to be serious if the participant claimed to have received medical attention from a health professional for their injury within 48 hours.

Injured participants were asked to report the type of injury; possible response options were multiple injuries, fractured bones, dislocations, sprains/strains, burn/scalds, cuts, scrape/bruise/blister, brain injury, and other. Fractured bones and dislocation were combined together for analyses. Outside of fractures/dislocations and sprains/strains, the occurrence of the other injury types were too infrequent $(<0.4 \%)$ to consider in the analyses. Participants were also asked to report the locations of their injury; possible response options were multiple locations, eyes, head, neck, shoulder, elbow, wrist, hand, hip, thigh, knee, ankle, upper back or spine, lower back or spine, chest, abdomen, and pelvis. For the analyses, these were grouped into the following categories: upper limbs (shoulder, upper arm, elbow, lower arm, wrist, and hand), lower limbs (hip, thigh, knee, lower leg, ankle, and foot), and torso (upper back or spine, lower back or spine, chest, abdomen, and pelvis). The incidences of injuries outside of these 3 regions were too infrequent to be considered in the analyses. Finally, injured participants were also asked if the injury was the result of a fall, and if not, what caused the injury. The latter question was used to assess whether the injury was the result of accidental contact or overexertion.

2.5. Confounding Variables. Based on past research and theoretical considerations, an array of potential confounders was included in the analyses: sex, age, type of occupation, race/ethnicity, smoking status, alcohol intake, income, education, and medical conditions. Age was considered as a continuous variable in most analyses; for stratified analyses, age was also considered as a categorical variable based on an approximate even split of the sample below and above $\geq 40$ years of age. Occupations were grouped into either sedentary (e.g., secretary, writer, and accountant), moderately active (e.g., nurse, retail salesperson, and flight attendant), or labour intensive (e.g., carpenter, commercial diver, and sawmill machine operator) from a more generalized list of 25 groups based on the 1991 Standard Occupational Classification [23]. Ethnicity was categorized in two groups (white and other). Alcohol intake was calculated based on the number of drinks consumed in the week prior to the interview and classified as nondrinkers (0 drinks), moderate drinkers ( 1 to 7 drinks), or heavy drinkers (8 or more drinks). Participants were considered current smokers if they smoked cigarettes at the time of the survey, former smokers if they were not currently smoking but had smoked more than 100 cigarettes in their life, and nonsmokers if they smoked less than this amount. Chronic medical conditions (comorbidities) were considered for inclusion; however, the incidence of these chronic conditions was too low to be considered during the modeling process.

2.6. Statistical Analysis. Conventional descriptive statistics were used to describe the characteristics of the study sample. Associations between BMI categories with occupational injuries (overall, serious, specific locations, specific types, and specific causes) were investigated using logistic 
regression analyses that were adjusted for sex, age, smoking, race/ethnicity, alcohol, income, education, and type of occupation. Stratified regression analyses were also performed according to sex, age group ( $<40$ versus $\geq 40$ years), and type of occupation. Sample weights were used for all analyses, and bootstrapping was used to determine the $95 \%$ confidence intervals. Population attributable risk (PAR) statistics were estimated based upon the observed prevalence of obesity in the participating Canadian workforce, and the estimated risks for occupational then serious occupational injury were observed. Analyses were performed using SAS version 9.1 (SAS Inc., Carry, NC, USA) and were powered to detect an effect size (OR) of 1.5 or more for obese versus normal weight participants, based upon baseline prevalence values and an alpha of 0.05 .

\section{Results}

Characteristics of the Canadian workforce population who participated in the 1998 and 2000 cycles of the NPHS are described in Table 1. More than half of the participants were male, less than 40 years of age, employed in sedentary occupations, and either overweight or obese. Within the 12 months prior to completing the 2000 survey, $3.6 \%$ of the participants suffered an occupational injury. Sprains and strains was the most frequent type of injury, the lower limb was the most common injury location, and accidental contact was the most frequent cause of the injuries.

Table 2 summarizes the estimated effects of overweight and obesity on the occurrence of occupational injury in Canadian workers. Obesity was associated with an approximately 1.5 -fold increase in the adjusted relative odds of serious occupational injury; much of this increase was attributable to specific types, anatomical sites, and external causes of injury. In particular, obesity was associated with increased odds of sprains and strains, injuries to the torso and lower limbs, falls, and overexertion injuries. Relationships between overweight and occupational injury were less consistent, with only one type of injury (injuries to the torso) associated with overweight BMI status.

Table 3 presents further analyses stratified by gender, age group, and type of occupation. The effects of BMI status on injury were most pronounced for women, workers $\geq 40$ years of age, and workers employed in sedentary occupations. This was observed for both occupational injury and serious occupation injury outcomes.

PAR estimates, which were calculated based upon the adjusted risk estimates and observed prevalence of obesity, were $8 \%$ for any occupational injury and $10 \%$ for serious occupational injury within the entire cohort. The corresponding PAR estimates were $16 \%$ for each type of injury among female workers, $19 \%$ and $15 \%$, respectively, among workers $\geq 40$ years old, and $15 \%$ and $17 \%$, respectively, among those employed in sedentary occupations.

\section{Discussion}

The primary finding of this national Canadian study was that obese workers experienced injury risks that were
TABLE 1: Description characteristics of workforce within the 19982000 National Population Health Survey $(N=7,678)$.

\begin{tabular}{|c|c|}
\hline Variable & Prevalence (\%) \\
\hline Gender, \% men & 56.1 \\
\hline Race, $\%$ white & 89.9 \\
\hline \multicolumn{2}{|l|}{ Age } \\
\hline$<40 y$ & 51.8 \\
\hline$\geq 40 \mathrm{y}$ & 48.2 \\
\hline \multicolumn{2}{|l|}{ BMI } \\
\hline Normal & 39.0 \\
\hline Overweight & 40.0 \\
\hline Obese & 21.0 \\
\hline \multicolumn{2}{|l|}{ Alcohol consumption } \\
\hline Nondrinker & 30.6 \\
\hline Light drinker & 38.7 \\
\hline Heavy drinker & 16.4 \\
\hline No response & 14.3 \\
\hline \multicolumn{2}{|l|}{ Smoking status } \\
\hline Smoker & 30.3 \\
\hline Former smoker & 26.0 \\
\hline Nonsmoker & 43.7 \\
\hline \multicolumn{2}{|l|}{ Family income } \\
\hline Low & 6.4 \\
\hline Low-moderate & 20.5 \\
\hline Moderate-high & 39.0 \\
\hline High & 28.2 \\
\hline Not reported & 5.9 \\
\hline \multicolumn{2}{|l|}{ Type of occupation } \\
\hline Sedentary & 53.3 \\
\hline Some activity & 20.6 \\
\hline Labour intensive & 26.1 \\
\hline \multicolumn{2}{|l|}{ Occupational injuries } \\
\hline Any injury & 3.6 \\
\hline Serious injuries & 2.7 \\
\hline \multicolumn{2}{|l|}{ Type of injury } \\
\hline Broken bone/fracture & 0.5 \\
\hline Sprain/strain & 1.5 \\
\hline \multicolumn{2}{|l|}{ Location of injury } \\
\hline Upper limb & 1.1 \\
\hline Lower limb & 1.2 \\
\hline Torso & 0.7 \\
\hline \multicolumn{2}{|l|}{ Cause of injury } \\
\hline Fall & 0.8 \\
\hline Overexertion & 0.7 \\
\hline Contact & 1.5 \\
\hline
\end{tabular}

approximately $40-49 \%$ higher than their normal weight counterparts. More substantial elevations in the risks of injury associated with obesity were observed among women, workers over the age of 40 , and workers employed in sedentary occupations. External causes of injury that accounted for these differences in risk included overexertion injuries and falls, typically resulting in injuries to the torso (lower 
TABle 2: Associations between BMI status and different types, anatomical sites, and causes of occupational injury, 1998-2000 National Population Health Survey $(N=7,678)$.

\begin{tabular}{|c|c|c|c|}
\hline & Normal weight (39.0\%) & Overweight (40.0\%) & Obese $(21.0 \%)$ \\
\hline Any occupational injury & 1.00 & $1.00(0.72-1.40)$ & $1.40(0.98-1.99)$ \\
\hline Serious occupational injury & 1.00 & $1.10(0.73-1.65)$ & $1.49(0.99-2.26)$ \\
\hline \multicolumn{4}{|l|}{ Type } \\
\hline Broken bone or dislocation & 1.00 & $0.86(0.12-6.16)$ & $1.44(0.52-3.99)$ \\
\hline Sprain or strain & 1.00 & $1.20(0.74-1.97)$ & $1.80(1.04-3.11)$ \\
\hline \multicolumn{4}{|l|}{ Anatomical site } \\
\hline Upper limb & 1.00 & $0.51(0.28-0.91)$ & $0.75(0.40-1.40)$ \\
\hline Lower limb & 1.00 & $1.03(0.50-2.11)$ & $2.14(1.12-4.11)$ \\
\hline Torso & 1.00 & $2.39(1.26-4.54)$ & $2.36(1.13-4.93)$ \\
\hline \multicolumn{4}{|l|}{ External Cause } \\
\hline Fall & 1.00 & $1.61(0.67-3.91)$ & $2.10(0.86-5.10)$ \\
\hline Overexertion & 1.00 & $0.74(0.35-1.57)$ & $2.08(0.96-4.50)$ \\
\hline Contact & 1.00 & $0.75(0.45-1.25)$ & $0.77(0.41-1.44)$ \\
\hline
\end{tabular}

Data presented as odds ratios ( $95 \%$ confidence intervals). Odds ratios adjusted for age, gender, ethnicity, income, education, smoking, alcohol, and type of occupation.

TABle 3: Associations between BMI status and occupational injury in subgroups of the 1998-2000 National Population Health Survey $(N=7,678)$.

\begin{tabular}{|c|c|c|c|c|c|c|}
\hline & \multicolumn{3}{|c|}{ Any occupational injury } & \multicolumn{3}{|c|}{ Serious occupational injury } \\
\hline & Normal weight & Overweight & Obese & Normal weight & Overweight & Obese \\
\hline \multicolumn{7}{|l|}{ By sex: } \\
\hline Males & 1.00 & $0.99(0.66-1.50)$ & $1.13(0.71-1.79)$ & 1.00 & $1.02(0.63-1.67)$ & $1.24(0.71-2.18)$ \\
\hline Females & 1.00 & $0.91(0.47-1.76)$ & $2.01(1.11-3.64)$ & 1.00 & $1.15(0.55-2.14)$ & $2.02(0.97-4.20)$ \\
\hline \multicolumn{7}{|l|}{ By age: } \\
\hline$<40$ & 1.00 & $0.83(0.53-1.30)$ & $1.15(0.70-1.88)$ & 1.00 & $1.00(0.57-1.74)$ & $1.33(0.73-2.45)$ \\
\hline$\geq 40$ & 1.00 & $1.40(0.83-2.35)$ & $1.96(1.11-3.47)$ & 1.00 & $1.24(0.68-2.26)$ & $1.69(0.87-3.26)$ \\
\hline \multicolumn{7}{|l|}{ By occupation: } \\
\hline Sedentary & 1.00 & $1.05(0.64-1.71)$ & $1.88(1.06-3.34)$ & 1.00 & $1.16(0.65-2.08)$ & $2.05(1.06-3.98)$ \\
\hline Moderately active & 1.00 & $1.06(0.43-2.62)$ & $1.22(0.50-3.00)$ & 1.00 & $1.44(0.46-4.56)$ & $1.13(0.37-3.44)$ \\
\hline Labour intensive & 1.00 & $0.87(0.51-1.49)$ & $1.02(0.57-1.81)$ & 1.00 & $0.86(0.44-1.66)$ & $1.08(0.52-2.25)$ \\
\hline
\end{tabular}

Data presented as odds ratios ( $95 \%$ confidence intervals). Odds ratios were adjusted for age, gender, ethnicity, income, education, smoking, alcohol, and type of occupation, as appropriate.

back) and lower limbs. Up to $19 \%$ of the observed risks for occupational injury were attributable to obesity within highrisk subgroups of the working population.

Our findings were consistent with many aspects of our previously developed biophysical framework which provided a theoretical base for our analyses [11]. In that framework, it was suggested that obesity includes a combination of risk and protective factors that would lead to varying risks for specific external causes of injury, including falls and sprains and strains. Major protective factors involved are increased bone density and cushioning from fat, and indeed this may have translated into some minimization of risk for fractures, as evident in the lack of association between obesity and broken bones/dislocations. Major risk factors involved include direct and indirect physical effects of obesity and its treatment including walking and balance problems, lower neural sensitivity, the psychotropic effects of some medications, and the sleepiness and fatigue attributable to sleep apnoea. These conditions would be expected to lead to injury patterns consistent with the effects observed here for women, sedentary workers, and older workers. Our failure to identify such associations for male and younger workers, however, suggests that the theory underlying this biophysical framework may not apply equally to all members of the working population. Further, the lack of any consistent associations between overweight status and injury suggests that a threshold may exist whereby only those workers with the highest BMI values are vulnerable. At this stage and consistent with past findings [11], this framework should be applied with caution to future studies that examine the obesity-injury relationship.

Of the existing occupational studies that examine relationships between obesity and injury, most are limited in scope and size and are cross-sectional in design (e.g., [710]). A notable exception is the retrospective cohort study of 11,728 health care and university employees conducted 
by Ostbye and colleagues [24]. Within that study, there was a linear relationship between BMI and the rate of workers' compensation claims attributable to injury. Workers with class 1 obesity (BMI $30-34.9 \mathrm{~kg} / \mathrm{m}^{2}$ ) had 8.8 claims per 100 full-time equivalents compared to 5.8 claims for workers with a normal BMI. Collectively, the findings from previous studies suggest a modest increase in risk for injury associated with obesity. Consistent with our findings, previous studies have suggested that the risks associated with obesity differ depending on the type of injury [7, 24], site of injury $[7,24]$, and mechanism of injury [24].This suggests a need to study the specific aetiologies of a variety of injury types and demographic subgroups, as well as different natures and mechanisms of injury, to fully understand the etiological relation between obesity and occupational injury risk.

The implications of our study findings for workplace health policy warrant comment. If the relationships under study are accurate and causal in nature, the PAR estimates indicate that approximately one in ten occupational injury events in the Canadian workforce are directly attributable to obesity, with up to one in five occupational injuries being attributable to obesity in susceptible population subgroups. We are unaware of previous studies that have attempted to estimate PAR estimates for workplace injury attributable to obesity. These PAR estimates are of substantial importance given the high frequency and costs of occupational injuries. In Canada, from 1996 to 2005, an average of almost one million time-loss injury claims were reported each year by provincial or territorial Worker's Compensation Boards; on average, 366,459 of these were accepted for compensation [25]. The annual cost of occupational injuries to the Canadian economy has been estimated to be over $\$ 13.5$ billion [25].

There are two primary avenues by which employers could help reduce the burden obesity has on occupational injury. First, employers should consider how obesity impacts and interacts with other salient and modifiable risk factors for workplace injury such as job and task design, physical environments, and social factors. For example, workstations can be designed to be ergonomically sound for heavier persons and not just the average person. Second, employers should consider adopting or expanding workplace wellness initiatives aimed at improving physical activity and eating behaviours in their workforce. At present, only a small percentage of Canadian employers incorporate comprehensive workplace wellness initiatives, perhaps because they do not see these initiatives as being good for the bottom line [26]. Although the medical services associated with workplace injury in Canada are covered by our public health care system and not the employer or its insurance provider, employers need to recognize that investments into workplace wellness initiatives could still have a favourable impact on the bottom line by reducing absenteeism and lost productivity.

Our study builds upon noted gaps in the literature. It was large, nationally representative, longitudinal in design, provides estimates for specific types and external causes of injury, examined subgroups of the population that appear to be particularly vulnerable, and the etiological analyses were theory driven. Noted limitations of our study include exposure and outcome misclassification that is typical of all surveys that rely upon self-report measures. Because this was a general health survey without stated hypotheses, the latter would be expected to bias observed risk estimates toward no effect. The study was also limited by our inability to produce stable estimates of effect for specific types of injury (e.g., fractures and dislocations to lower limbs; strains and sprains to the lower back) within population subgroups due to sample size constraints. Furthermore, as the number of participants with a BMI $\geq 35 \mathrm{~kg} / \mathrm{m}^{2}$ (class II or III obesity) was small, we were unable to examine injury risks at the most extreme levels of obesity. Finally, our study relied on BMI as the measure of obesity. Other measures of obesity, such as the waist circumference, tend to be more strongly related to obesity-related health outcomes [27].

\section{Conclusions}

This national study points to the potential importance of obesity in the aetiology of occupational injury. The results provide evidence of use to research communities in the obesity, injury prevention, and occupational health fields. Study findings include novel data surrounding the proportion of occupational injury attributable to obesity, as well as high-risk groups that are particularly vulnerable and hence merit attention via focused prevention efforts.

\section{Conflict of Interests}

The authors declare that they have no conflict of interests.

\section{Acknowledgments}

This study was supported by a pilot project grant from the Canadian Institutes of Health Research (CIHR). I. Janssen was supported by investigator awards from CIHR and the Ontario Ministry of Research and Innovation.

\section{References}

[1] M. Tjepkema, "Adult obesity," Health Reports, vol. 17, no. 3, pp. 9-25, 2006.

[2] M. Shields, "Overweight and obesity among children and youth," Health Reports, vol. 17, no. 3, pp. 27-42, 2006.

[3] K. M. Rexrode, J. E. Buring, and J. E. Manson, "Abdominal and total adiposity and risk of coronary heart disease in men," International Journal of Obesity and Related Metabolic Disorders, vol. 25, pp. 1047-1056, 2001.

[4] W. B. Kannel, R. B. D’Agostino, and J. L. Cobb, "Effect of weight on cardiovascular disease," American Journal of Clinical Nutrition, vol. 63, no. 3, 1996.

[5] J. M. Chan, E. B. Rimm, G. A. Colditz, M. J. Stampfer, and W. C. Willett, "Obesity, fat distribution, and weight gain as risk factors for clinical diabetes in men," Diabetes Care, vol. 17, no. 9, pp. 961-969, 1994.

[6] P. T. Katzmarzyk and I. Janssen, "The Economic costs associated with physical inactivity and obesity in Canada: an update," Canadian Journal of Applied Physiology, vol. 29, no. 1, pp. 90-115, 2004. 
[7] K. M. Pollack, G. S. Sorock, M. D. Slade et al., "Association between body mass index and acute traumatic workplace injury in hourly manufacturing employees," American Journal of Epidemiology, vol. 166, no. 2, pp. 204-211, 2007.

[8] E. S. Soteriades, R. Hauser, I. Kawachi, D. C. Christiani, and S. N. Kales, "Obesity and risk of job disability in male firefighters," Occupational Medicine, vol. 58, no. 4, pp. 245250, 2008.

[9] A. Bhattacherjee, N. Chau, C. O. Sierra et al., "Relationships of job and some individual characteristics to occupational injuries in employed people: a community-based study," Journal of Occupational Health, vol. 45, no. 6, pp. 382-391, 2003.

[10] B. N. Craig, J. J. Congleton, C. J. Kerk, A. A. Amendola, and W. G. Gaines, "Personal and non-occupational risk factors and occupational injury/illness," American Journal of Industrial Medicine, vol. 49, no. 4, pp. 249-260, 2006.

[11] D. R. Bouchard, W. Pickett, and I. Janssen, "Association between obesity and unintentional injury in older adults," Obesity Facts, vol. 3, no. 6, pp. 363-369, 2010.

[12] I. Janssen, "Morbidity and mortality risk associated with an overweight BMI in older men and women," Obesity, vol. 15, no. 7, pp. 1827-1840, 2007.

[13] A. Dzien, K. P. Pfeiffer, C. Dzien-Bischinger, F. Hoppichler, and M. Lechleitner, "The influence of obesity on the frequency and distribution of medication," Acta Medica Austriaca, vol. 30, no. 2, pp. 51-54, 2003.

[14] D. R. Bouchard, I. J. Dionne, and M. Brochu, "Sarcopenic/obesity and physical capacity in older men and women: data from the nutrition as a determinant of successful aging (nuage)the quebec longitudinal study," Obesity, vol. 17, no. 11, pp. 2082-2088, 2009.

[15] M. P. Slovenkai, "Foot problems in diabetes," Medical Clinics of North America, vol. 82, no. 4, pp. 949-971, 1998.

[16] P. Spyropoulos, J. C. Pisciotta, K. N. Pavlou, M. A. Cairns, and S. R. Simon, "Biomechanical gait analysis in obese men," Archives of Physical Medicine and Rehabilitation, vol. 72, no. 13, pp. 1065-1070, 1991.

[17] R. D. Vorona, M. P. Winn, T. W. Babineau, B. P. Eng, H. R. Feldman, and J. C. Ware, "Overweight and obese patients in a primary care population report less sleep than patients with a normal body mass index," Archives of Internal Medicine, vol. 165, no. 1, pp. 25-30, 2005.

[18] D. T. Felson, Y. Zhang, M. T. Hannan, and J. J. Anderson, "Effects of weight and body mass index on bone mineral density in men and women: the Framingham study," Journal of Bone and Mineral Research, vol. 8, no. 5, pp. 567-573, 1993.

[19] Statistics Canada, "Inforamation about the National Population Health Survey," Statistics Canada, Ottawa, ON, 1999.

[20] S. Connor Gorber, M. Shields, M. S. Tremblay, and I. McDowell, "The feasibility of establishing correction factors to adjust self-reported estimates of obesity," Health Reports, vol. 19, no. 3, pp. 71-82, 2008.

[21] World Health Organization, "Obesity: Preventing and Managing the Global Epidemic," Report of a WHO Consultation on Obesity, Geneva, 1998.

[22] Health Canada, "Canadian Guidelines for Body Weight Classification in Adults," Canada Publications Centre, Ottawa, ON, 2003.

[23] Statistics Canada, "Standard occupational classification," Statistics Canada, Ottawa, ON, 1991.

[24] T. Ostbye, J. M. Dement, and K. M. Krause, "Obesity and workers' compensation: results from the duke health and safety surveillance system," Archives of Internal Medicine, vol. 167, no. 8, pp. 766-773, 2007.
[25] Human Resources and Social Development Canada, "Occupational Injuries and Diseases in Canada, 1996-2005," Human Resources and Social Development Canada, Ottawa, ON, 2007.

[26] E. Morrison and N. J. MacKinnon, "Workplace wellness programs in Canada: an exploration of key issues," Healthcare Management Forum, vol. 21, no. 1, pp. 26-32, 2008.

[27] I. Janssen, P. T. Katzmarzyk, and R. Ross, "Waist circumference and not body mass index explains obesity-related health risk," American Journal of Clinical Nutrition, vol. 79, no. 3, pp. 379-384, 2004. 


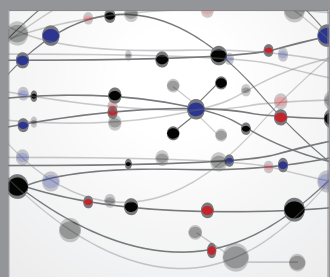

The Scientific World Journal
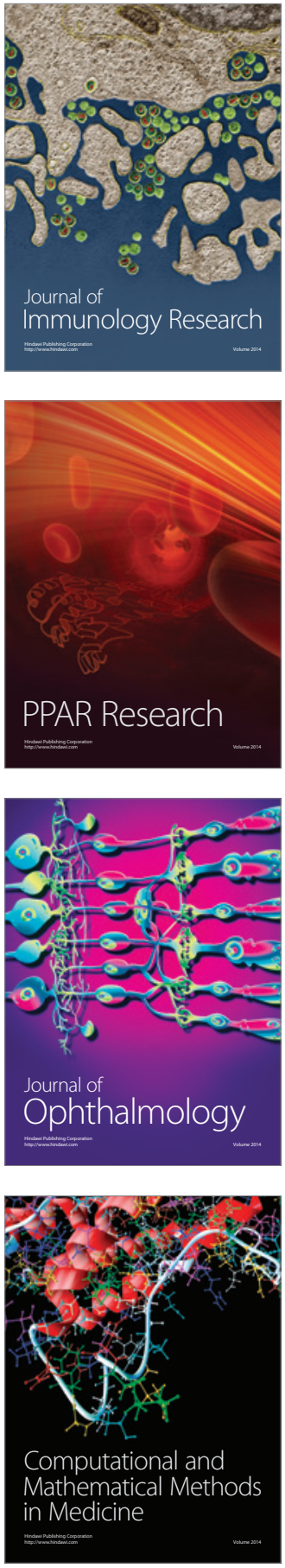

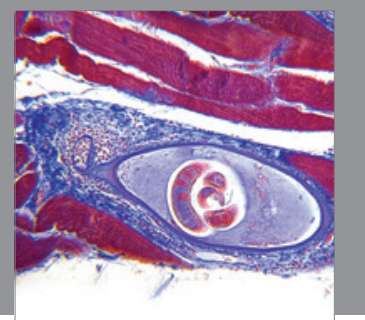

Gastroenterology

Research and Practice
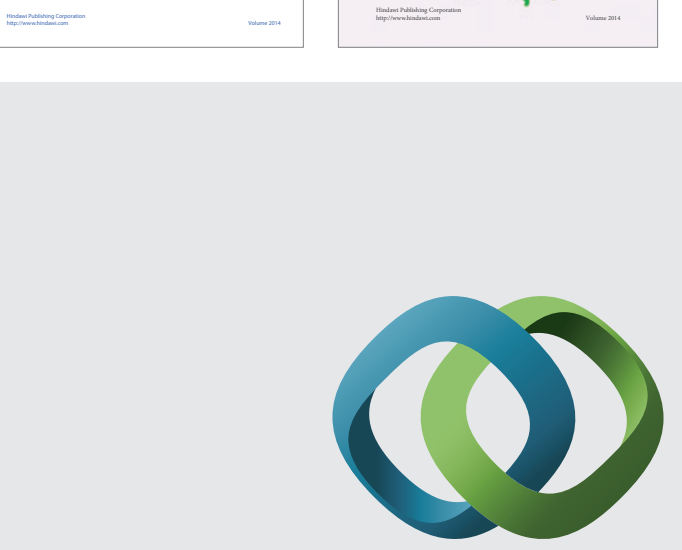

\section{Hindawi}

Submit your manuscripts at

http://www.hindawi.com
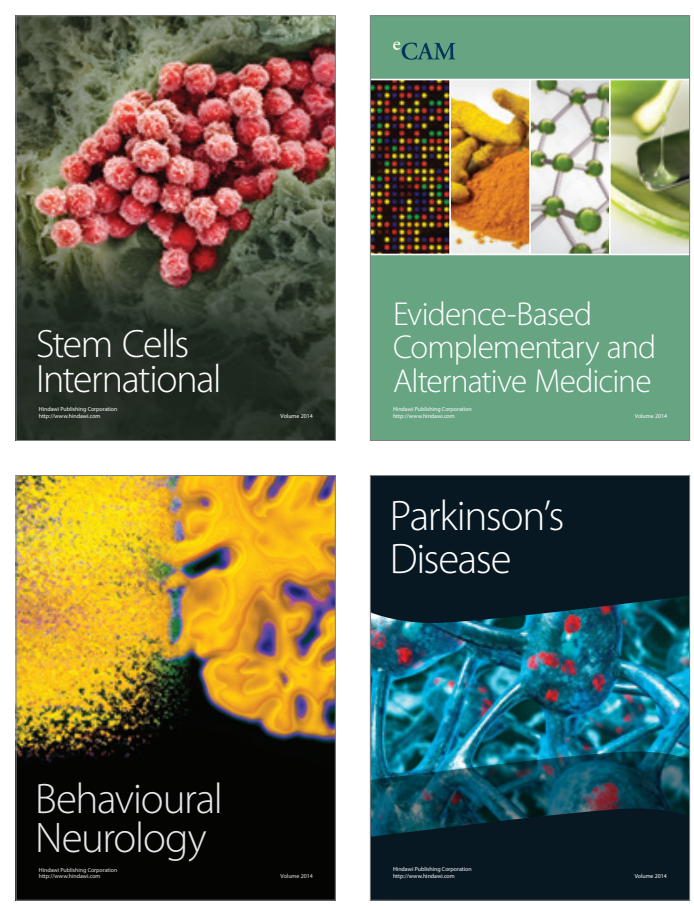

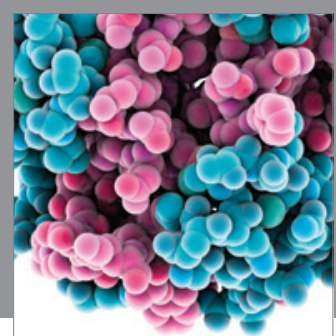

Journal of
Diabetes Research

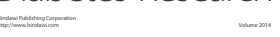

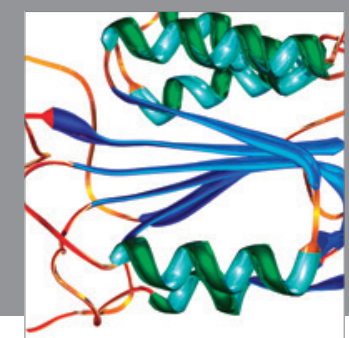

Disease Markers
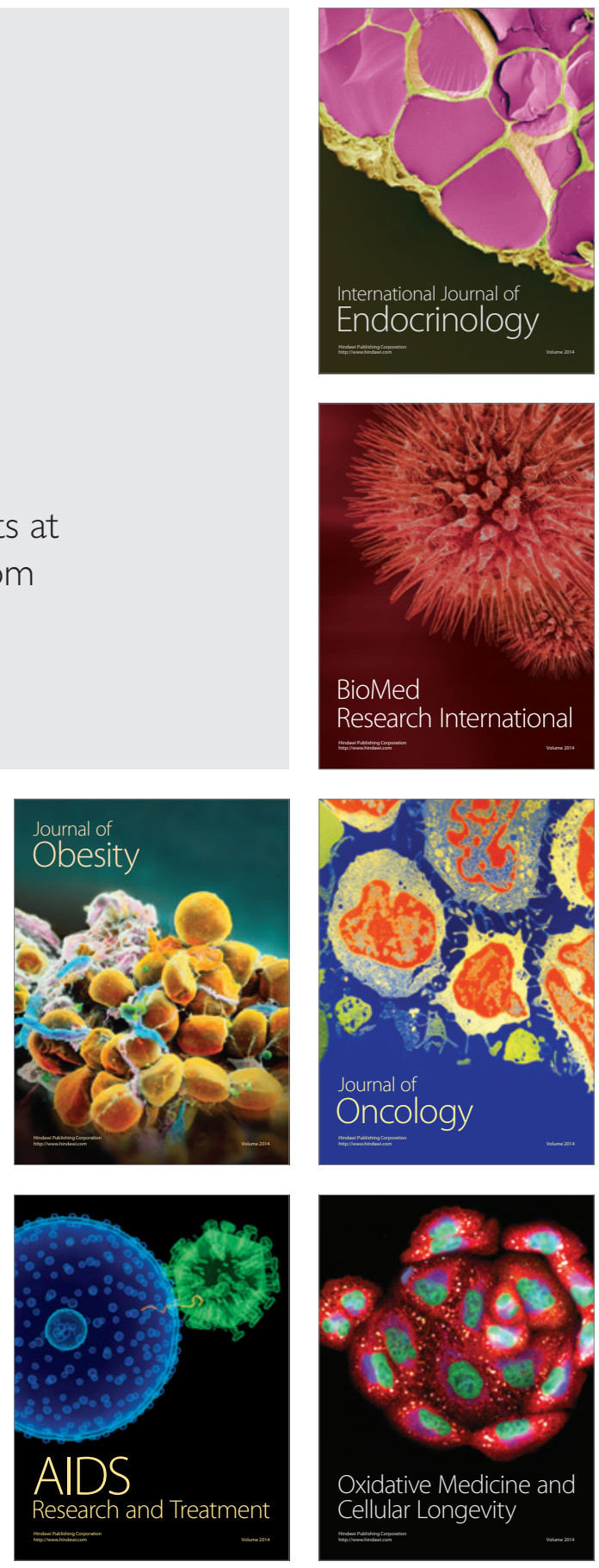